tion and when this is noticed, in from three to five minutes, the process is completed and the paste is rinsed off with warm water.

'The eflicacy of this method of treating the hands is attested by the bacteriological tests employed by I)r. Weir. Forty-two tests gave forty sterile results, or ninety-five per cent. of successful results. These figures are to be compared with a series of thirty-one tests made by the same observer under the same conditions with permanganate of potash (1 to 16) and oxalic acid. In these, twenty-two were sterile, or seventy per cent. Howard kélly, in a series of fifty experiments with permanganate and oxalic got germ free result,s in forty-four, or eighty-eight per cent., a somewhat better showing, but still not as good as the results in the experiments with lime and soda.

Some operators object to the chlorine process because of the odor of the chlorinated lime, others hecause of a fear that caustic soda will affect, the skin injuriously. One very soon gets accustomed to the odor of the lime, so that it, is not disagreenble, and the fear as to the injurious effect of the soda on the skin can bo quickly dispelled by making trial of the process. It is possible, to be sure, to make the skin very sore by prolonged scrubbing with wishing soda, especially if a new and stiff nail-brush of vegetable fibre is used, but this is not the way in which it is advised to use the soda. I have repeatedly used the lime and soda three and four times in a day without in any way irritating my skin, which, by the way, is thinner than the average. Permanganate and oxalic used once a day for several days in succession ure sure to set, up a dermatitis.

The permanganute and oxalic method has one advantage over all other methods of disinfecting the hands and that, is, that it cannot well be slighted. When the hands are once dyed a deep brown color they must bo decolorized, and in the process sterilized, and thus the patient is protected from the surgeon who hasu't an aseptic conscience. But as such surgeons have no just right to operate and, fortunately, are becoming searcer every day, this property of the permanganate and oxalic will soon cease to be an advantage.

I have no bacteriological tests of my own to present in support of the lime and soda method but from a clinical experience of its uso of over a year aud a half I am unqualifiedly in favor of it.

In closing I should like to say once more that the hands should be always kept cleau, relatively aseptic, and that it is nearly as important to wash the hands after an operation as it is before.

\section{Alinical Department.}

\section{TWO CASES OF INFAN'TITE BI,ADDER 'TREA'ILI) BY (GRADUAI, DIS'TEN'TION.'}

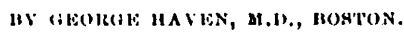

InCONTINENCE of urine is very frequent in children, but, usually does not persist after the latter part of childhood. Little is known regarding the cause in the earlier years, but it is commonly attributed to overacidity of thes urine, hahit, debility, otc.

The treatment of incontinence in the early years of

2 Read boforo the Obstetrinil socioty of Boston, Mruroh 21, 1899. childhood is unsatisfactory, and is directed, as a rule, to reducing irritation at the neck of the bladder, and to general hygienic principles. 'The fow cases which persist after puberty have been the opprobria of the physicians, for the reason that in few of these cases has the size of the bladder been taken into account. It is very fair to suppose that in a majority of these cases where the health of the patient is all that can be desired, and where the urine is normal, a contracted bladder space is responsible for the unpleasant condition. The normal capacity of the bladiler is hard to determine, but various observers place the amount which the bladder should hold at between twelve and sixteen ounces, and under pressure at from fifteen to twenty ounces. Bladders have ruptured in the cadaver under a pressure exerted hy from a quart to three pints of water.

The two cases which I have to report occurred in girls of eighteen years of age. Incontinence had been present from birth, and the bed had been wet almost overy night. Their condition was pitiful, as they were unable to visit, go to the theatre, or spend a night in a bed unprotected by a rubber blanket.

Casl: I. Miss R., age seventeen and a half yeurs, had passed urine in bed every night from birth, and was unable to retain it longer than one hour during the day. 'Treatment was begun the 29th of March, 1890, and was continued until August 30th of the same year. She was seen every other day, and the bladder was distended by injecting into it a four-per-cent. solution of borncic acid to the point of great physical discomfort. The bladder at first held eight ounces under pressuro. On May 8th nineteen ounces were injected, and on May 2 lst twenty ounces were introduced. This treatment was continued, and on the fourth of June, 1892 , she reported that she could hold her urine from five to six hours during the day, and almost always during the night. A later report from her is most satisfactory, as she is perfectly woll, having no trouble by day or night.

Case 11. Miss C., eighteen years old, was referred to mo by 1)r. 'T. M. Rotch on the 1!th of November, 1898. She had wot her bed constantly from hor carliest years, and was somewhat depressed by her condition. 'The bludder held about three and a half ounces of water, and six ounces caused distinct pain and discomfort. 'The treatment consisted of injecting a four-per-cent. solution of boracic acid into the bladder until the discomfort was so great that no moro could be held. It was rotained in the beginning from ten to fifteen minutes, and later from twenty to thirty minutes. At first the maximum amount was not over oight ounces. The bladder was distended every other day, and at the time of writing the patient has had sixteen days of immunity from incontinence, and tho bladder holds abont twenty ounces under pressure.

The only instruments needed are a male catheter cut down to about five inches, a piece of rubber tubing to comect it with the end of a I )avidson sy ringe, and a solution of boracic acid. 'Tho resistance of the bulb to pressure is a very good guide to the pressure in the blaider.

The treatment of contracted or infantile bladders by graulual distontion was, I believe, first spoken of by I)r. Sims the younger, and he has reported one or two cabes in the American, Journal of Obstetrics with very favorable results. (ases of infantile bladiler are rare, possibly because they aro vory often overlooked, and 
the condition remains unrelieved, although treated by drugs, etc. It is a pathological condition, and fortunately, as the bladder is elastic, can be overcome by dilatation.

I have no record regarding the internal appearance of the bladder in the first case. In the second case the bladder was absolutely normal.

\section{grodical Orogregæ.}

\section{REPOR'T ON PROGRESS IN PHYSIOLOGICAI CIIEMISTRY.}

nY H. F. HEW MA, M.D., BOETON.

(Concluled from No, 22, p. 524.)

THE FORMATION OF AILANTOIN AS THE RESULT OF NUCLEIN METABOLISM.

Of the amount of nitrogen contained in the nuclein, rich substances, as calf's thy mus, ingested by man, Weintraud found that a trace only (one-fifth to one-fourth per cent.) appears in the urine in the form of uric acid. $\Lambda$ part, perhaps the greater part, is transformed to urea. 'There can be no questions from the investi gations of Weintraud, Frerichs, and others that large amounts of uric acid are thus further oxidized in the system.

$\Lambda$ part also appears in the urine in the original form of xanthin bases, xauthin, hypoxanthin, etc.

Ileretofore these substances, urea, uric acid and the xanthin or alloxur bases, have been considered as the only important nitrogenous end products of the metabolism of nuclein in the animal body. Minkow$8 \mathrm{ki}^{2 \mathrm{k}}$ however, in some very recent investigations has shown that still another end product from this substance may appear in the urine.

In the urine of dogs fed with a substance rich in nuclein (calf's thymus) this observer found as a constant appearance, besides the above-mentioned nitrogenous products, still another organic nitrogenous substance, which upon analysis proved to be allantoin. 'This allantoin is an oxidation product of uric acid. It has been found in the urine of mammale, even of man, by Salkowski and others. But, as a rule, it has been entirely overlooked in investigations of the nitrogenous excretions, the nitrogen not found as uric acid or alloxur bases being all computed as urea. 'These observations of Minkowski's show that in dogs with nuclein feeding this allantoin appears in large amounts in the urine, while the uric-acid excretion is but moderutely increased.

In men, under the same conditions of nuclein feeding, Minkowski found a markedly increased uric-ucid excretion aud no allantoin. Dogs fed with allantoin show a marked increase of this substance in the urine. Men fed with allantoin show no allantoin in the urine. 'The substance is here probably oxidized to urea.

'This observation of Minkowski's is of great importance in the investigations of this question of nuclein metabolism. 'The increased allantoin excretion upparentily has the same significance in dogs under nuclein foeding that the incrcased uric acid las in man. Allantoin is not an important element in the normal

2s Minkowski : Archiv f, exp. Pnthologlo und Pharmakologio, 13a, xli, H. vi, December, 1808. Untersuohungen zur Physiologie und Iathologio dor Hamsiine boi Sangethioren. nitrogenous excretions of man, but may be found to be 80 in pathological conditions.

\section{THE CONSTITUTION OF 'THI SIMPLEST PROTWIDS.}

Of the three classes of organic compounds which enter into the constitution of living substance, the fats, carbohydrates and proteids, two only, the fats and carbohydrates, have up to the present time been thoroughly understood as regards their chomical constitution and the method of their formation. 'The determination of the constitution of the third, the proteids, has been one of the most difficult problems of physiological chemistry. 'The investigations of Kossel ${ }^{21}$ during tho last few years have, however, done much to solve this question, and will in all probability when completed place our understanding of the nature of these proteids upon a level with that of the fats and carbolyydrates.

Among the decomposition products of proteids and proteid substances are some certain basic decomposition products which are common to all proteids. We can assume therefore that these substances form the nucleus of the proteid molecule, about which the various proteids are built up, or at least that there is a definite atom complex in this combination of ultimate constituents which forms this nucleus. 'To determine the constitution of this nucleus we must investigate those proteid compounds in which these common constitutents, the basic products, are present in their greatest purity. Such simple proteids Kínsel has found in the protamines, compounds obtained by him, from the spermatozoa of the salmon, sturgeon, and herring. 'These protamines are constituents of the nuclei of these sperm cells, being combined with nucleinic acid to form the chromatin of the nuclei.

According to Kossel, clupein, the protamin obtuined from the lierring sperm, has the empirical formulat $\mathrm{C}_{30} \mathrm{H}_{57} \mathrm{~N}_{17} \mathrm{O}_{\mathrm{B}}$.

Tho atom complex of protumin is present in all proteids. 'The protamin contained in these proteids is the source of the common basic decomposition products which represent the nucleus of proteid substance. Thus Kossel in investigating the constitution of this simplest proteid, protamin, finds that upon decomposition it yiclds three defivite basic products, which ho names the hexon bases. 'These are: lysin, $\mathrm{O}_{4} \mathrm{II}_{14}$ $\mathrm{N}_{22} \mathrm{O}_{2}$; histidin, $\mathrm{C}_{1 ;} \mathrm{H}_{4} \mathrm{~N}_{3} \mathrm{O}_{2}$; arginin, $\mathrm{C}_{43} \mathrm{II}_{14} \mathrm{~N}_{4} \mathrm{O}_{2}$. 'The protamin from the herring sperm, clupetu, contains one molecule of lysin, one molecule of histidin, and three molecules of arginin. This gives a formula of $\mathrm{C}_{3,0} \mathrm{I}_{6,5} \mathrm{~N}_{17} \mathrm{O}_{10}$, for the protamin, or the ompirical formula of clupein plus four molecules of water $\left(\mathrm{C}_{30} \mathrm{H}_{57} \mathrm{~N}_{17} \mathrm{O}_{6}+\mathrm{H}_{4} \mathrm{H} \mathrm{O}\right)$.

If we accept "Kossel's premises that the atom complex of protamin is a constituent of all proteids, these investigations lead us to conclude in regard to the mucleus of the proteid molecule, or the simplest proteid, first, that it, is some base-yielding combination of threo hexon bases, histidin, arginin and a base of the chemical grouping of lysin; second, that it gives the biuret reaction; third, that it is split up by tho action of trypsin.

Upon this nucleus the various proteid compounds are formed. 'The first group consists of the simplest proteids, as protamin, which contains the base-yielding group alone. In the second group we have this nucleus

2:1 A. Kossol : Zoitschr. f. phys. Chemie, 1898, vol. $x \times v$, p. 165, and vol. $x \times 1 i$, p. 17 i. 